\title{
COMO CANDIDATOS AO CURSO DE PSICOLOGIA PERCEBEM A PROFISSÃO ESCOLHIDA?
}

\section{HOW CANDIDATES FOR PSYCHOLOGY COURSE FEEL THAT IS THE RIGHT CHOICE?}

\author{
'Psicóloga. Doutora em Medicina e Saúde Humana. Docente na Escola Bahiana de Medicina e Saúde Pública. \\ Salvador, Bahia, Brasil.monicadaltro@bahiana.edu.br \\ ${ }^{2}$ Médica psiquiatra. Doutora em Saúde Coletiva. Docente na Escola Bahiana de Medicina e Saúde Pública. \\ Salvador, Bahia, Brasil. milenaponde@bahiana.edu.br
}

Mônica Ramos Daltro', Milena Pereira Pondé2

RESUMO I Esse artigo é parte de uma tese de doutoramento que investiga a dimensão subjetiva presente na formação em psicologia, esta etapa da pesquisa investigou a percepções candidato aos cursos sobre a profissão escolhida. Estudo descritivo, aprovado pelo CEP, parecer $\mathrm{n}^{\circ} 108.985$ Analisa 0 conteúdo de 54 fichas contendo a percepção sobre a psicologia, durante vestibular, de uma instituição privada, em Salvador-Bahia. Os resultados confirmam a literatura sobre a percepção da psicologia como profissão de ajuda. O sentido desta ajuda foi analisado e decorreram núcleos de sentido para a ação de ajudar: curativo, orientadora e mediadora. Constata-se que psicologia é percebida como plural, mas a partir de valores próprios da modernidade, fundamentados em um modelo de subjetividade de natureza binária que tende a responder às demandas do discurso biomédico e neoliberal hegemônicos na contemporaneidade

Palavras-Chave: Psicologia, Profissão de Saúde, Escolha Profissional.

\begin{abstract}
This article is part of a Doctorate Thesis that investigate the subjective dimension presented in the psychology formation, that part of the research worked on the candidates perception about the professions to be chosen. Describing study approved by the CEP ( $\left.N^{\circ} 108.985\right)$, analyses the content of 54 documents based on Psychology perception during the Entrance Test period of a private institution in Salvador, Bahia. The results confirm the literature of Psychology as a helping profession, and indentify three cores of helping sense: cure, orientation and mediation. It notes that Psychology is known as plural, parting from modernity own values, based on a model of Binary nature of subjectivity that implies in answer the demands of the hegemonic biomedical and neoliberal speech, which could not see the singularities process of the late modernity, described by Stuart Hall.
\end{abstract}

Key Words: Psychology, helping profession, Professional choices. 


\section{INTRODUÇÃO}

A identidade de uma profissão está dada por um conjunto de elementos que inclui imagens, sistemas de referência que circulam no ambiente sociocultural dando suporte à tradição profissional. Inclui, de forma decisiva, o sistema educativo de um país, com seus ideários políticos e ideológicos, assim como as dinâmicas coletivas existentes em cada território, que são validadas, ou não, pelo campo acadêmico'.

Para Stuart Hall ${ }^{2}$, as identidades dos sujeitos contemporâneos estão colocadas a partir da percepção de certa crise cuja essência refere o declínio de velhas identidades que, historicamente, estabilizaram o mundo social, enquanto novas identidades emergem revelando a natureza fragmentada e mutante do indivíduo moderno. Considerando que esse sujeito contemporâneo é objeto de estudo e intervenção da psicologia, propõe-se discutir: como ela se tem colocado frente a esses novos sujeitos? Como esses novos sujeitos percebem a psicologia? Quem são esses sujeitos que escolhem a profissão psicologia?

Esses e outros questionamentos orientaram o trabalho de reformulação curricular de um curso de psicologia em uma instituição privada de ensino superior na Bahia, Região Nordeste do Brasil, vinculada a uma Fundação, sem fins lucrativos, cujo processo é foco da investigação de uma tese de doutorado, da qual este artigo é parte. $O$ processo de reformulação curricular teve início com a presente investigação, que buscou conhecer a percepção dos candidatos ao curso de psicologia sobre a profissão escolhida com vista a alicerçar a construção de uma nova estrutura curricular.

Na literatura brasileira das últimas quatro décadas, candidatos ao curso de psicologia, hegemonicamente, afirmam a psicologia como profissão de ajuda ${ }^{3,4,5,6}$.

Essa representação que encarna a percepção do senso comum ${ }^{7}$, associa-se à representação hegemônica da psicologia como uma profissão de natureza clínica e privada, referida, também, em estudos realizados na Espanha, França e na América Latina $^{8,9,1,10,11}$. Esse panorama reflete os parâmetros ideológicos presentes nas estruturas formativas do psicólogo que, historicamente, vem se consolidando no campo da clínica do anormal e do patológico e a partir de práticas que assumem uma dimensão categorizadora e adaptativa ${ }^{12,13,14,11}$.

Essa imagem social da psicologia tem, no seu alicerce, uma concepção de sujeito que não corresponde ao sujeito contemporâneo, segundo Hall ${ }^{2}$, mas, ao sujeito do lluminismo, que compreende a pessoa humana como um indivíduo unificado, regido pela razão e pela consciência, própria ao positivismo. Descrito como masculino, esse sujeito é detentor de uma interioridade que define sua identidade. É nessa perspectiva iluminista, que a psicologia consolida-se como uma profissão da modernidade. No Brasil, essa racionalidade se apóia no ideário capitalista e adere ao modelo de atuação liberal privatista $^{10}$.

Para Lacan ${ }^{15}$, essa psicologia da consciência, do cógito, que faz menção a um modelo de subjetividade e sustenta a existência do sujeito holístico, vocacionado a ser feliz e ter sucesso, está forjada no discurso médico/laboratorial da modernidade que reduz as possibilidades identitárias da psicologia, pois restringe seu objeto a fins biológicos baseados em concepções científicas que precarizam o valor das produções subjetivas. Essa perspectiva tem tonificado os discursos sobre autoajuda, que se engendram à lógica do consumo, do individualismo e da cultura do narcísico que têm atravessado a imagem da psicologia.

O sujeito contemporâneo, descrito por Hall2, assim como a psicologia, não podem ser referenciada a partir de uma identidade fixa ou unificada, na medida em que a contemporaneidade produz significações e representações culturais que se multiplicam que são cambiantes, impermanentes, compostas não por uma, mas por múltiplas identidades, algumas, inclusive, contraditórias.

Lodieu, Scaglia e Santos' ${ }^{1}$, em um estudo sobre a representação social do psicólogo por estudantes argentinos-inspirados na teoria da representação social de Moscovici-chamam a atenção para a necessidade de desenvolver estudos que abordem as representações sociais, relacionando-as, ou não, ao imaginário social, que possam identificar o 
caráter simbólico da atividade representativa daqueles sujeitos que partilham aquela mesma condição ou experiência social, como estratégia de reconhecimento do sentido que dão à sua experiência no mundo social, concepção adotada nesta tese para fundamentar a construção de um modelo curricular que possa subsidiar uma formação que apresente a multiplicidade identitária da psicologia e, simultaneamente, inclua o conjunto de singularidades dos sujeitos que se oferecem a uma formação em psicologia.

Yamamoto, Falcão e Seixas ${ }^{16}$, descrevem o perfil identitário do estudante que ingressa em cursos de psicologia, no Brasil, como jovens, majoritariamente mulheres, de classe média e matriculados em instituições privadas. Essa é uma juventude que, segundo Birman ${ }^{17}$, tem suas referências identitárias ancoradas em registros sociais ligados ao consumo, ao individualismo, à espetacularização identitária, cujo pertencimento social está atrelado ao olhar do outro. Entretanto, são esses mesmos sujeitos que aparecem na literatura, afirmando escolher a psicologia com a intenção de ajudar. Não seria essa uma contradição? Será que a intenção de ajudar, atribuída à escolha pela psicologia está atrelada ao cuidado, aos valores, teoricamente próximos da religião, da solidariedade, da política ou ideais de transformação social? E a quem essa ajuda se endereça? Com vistas a problematizar essas questões, este artigo procurou conhecer a percepção de candidatos ao curso de psicologia sobre a profissão escolhida.

\section{MATERIAL E MÉTODO}

Estudo descritivo de abordagem qualitativa que analisa o conteúdo de 54 fichas contendo respostas à pergunta: Para você, ser psicólogo (a) é.... Os dados são parte do banco de dados institucional, relacionados ao processo do vestibular do primeiro semestre de 2011 para o curso de psicologia da Escola Bahiana de Medicina e Saúde Pública (CAAE 03670812.7.0000.5544). A análise documental foi aprovada institucionalmente, mediante carta de anuência. Os dados foram interpretados segundo análise de conteúdo, através do Método de Interpretação de Sentido ${ }^{18}$, que se inicia com um processo de apropriação textual realizada com a leitura compreensiva do conjunto do material, seguindo-se o levantamento das palavras, ações, conjunto de inter-relações e conjunturas do corpo analítico, a partir das quais são identificadas categorias que classificam o conteúdo conforme as particularidades do material que orientaram 0 processo de interpretação dos dados.

\section{RESULTADOS}

Entre as 54 fichas de candidatos ao curso de psicologia incluídos neste estudo, $85 \%(46)$ tinham idade de 17 a 19 anos, $10 \%(5)$ de 20 a 25 e, $5 \%(3)$ maiores de 40 anos; $89 \%$ (48) da amostra é do sexo feminino.

$\mathrm{Na}$ leitura compreensiva do conjunto de fichas, observou-se que a palavra ou ação de ajudar esteve presente em $95 \%$ das 54 frases analisadas. Nos $5 \%$ restantes apareciam as palavras compreender, adquirir conhecimento ou informação. A categoria ajuda no contexto das respostas analisadas, identifica, simultaneamente, o fazer do psicólogo e o objeto de estudo da psicologia, descrito a partir de palavras como mente, paciente, pessoa, ser humano. A análise interpretativa do sentido das palavras possibilitou a classificação de três distintos núcleos de sentido para a categoria ajuda: curativa, orientadora e mediadora apresentadas na Tabela 1. 
Tabela 1. Apresentação das categorias de sentido atribuídas à ação de ajudar em psicologia

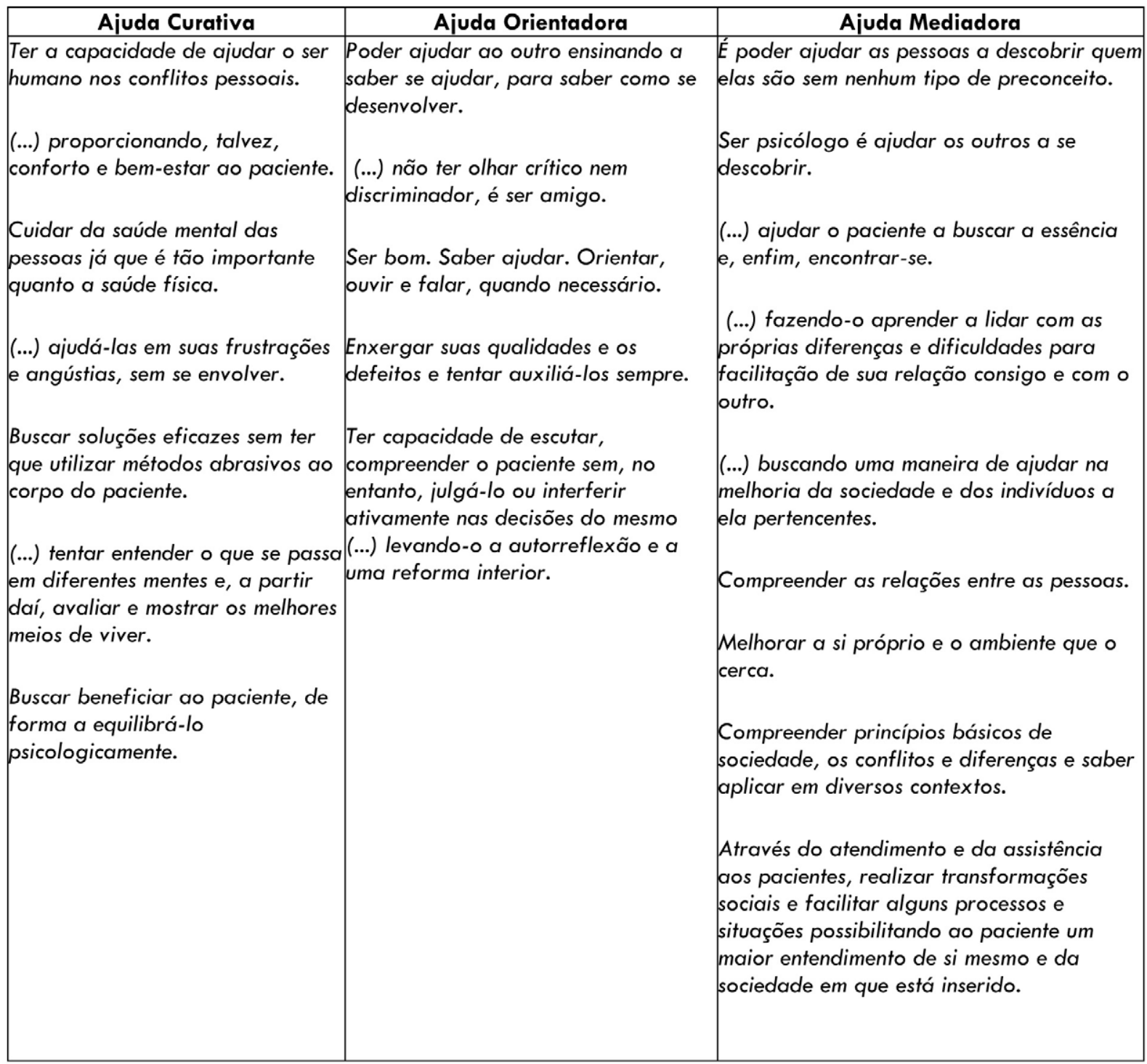

O sentido de ajuda curativa refere-se a respostas que incluem palavras como paciente, doença, trauma indicativo de que o fazer do psicólogo está relacionado a uma prática de cura e cuidados relacionados ao adoecimento ou patologias, como descrito no exemplo, a seguir:

Ajudar a tratar a mente das pessoas melhorando seus traumas, doenças, dúvidas e, também, levar a pessoa a se encontrar.

O sentido da ajuda orientadora identifica a ação do psicólogo dirigida a modificações de comportamentos e atitudes, pressupõe uma menor autonomia do outro e contempla referenciais prévios de melhorias:

(...) tentar entender o que se passa em diferentes mentes e, a partir daí, avaliar e mostrar os melhores meios de viver Compreender melhor determinadas situações e, assim, saber administrá-las, ser mais tolerante, poder ajudar as pessoas ouvindoas e aconselhando-as.

Poder ajudar ao outro ensinando a saber se ajudar, para saber como se desenvolver.

O sentido da ajuda mediadora está identificado em respostas que apontam para $\circ$ fazer em psicologia que considera a autonomia potencial do outro e se realiza facilitando o processo individual a partir de certa neutralidade. Evidencia o homem como sujeito em permanente interação com o ambiente e o fazer do psicólogo construído nessa interação com o mundo: 
Ajudar a desvendar e entender a vida e buscar melhorias no modo de encarar as adversidades e obstáculos.

Compreender princípios básicos de sociedade, os conflitos e diferenças e saber aplicar em diversos contextos.

Através do atendimento e da assistência aos pacientes, realizar transformações sociais e facilitar alguns processos e situações possibilitando ao paciente um maior entendimento de si mesmo e da sociedade em que está inserido.

\section{DISCUSSÃo}

O perfil dos sujeitos que participaram deste estudo está em acordo com a literatura ${ }^{16}$, e a percepção deles em relação à psicologia e, também, confirma os estudos realizados pela literatura brasileira, nas últimas quatro décadas, nos quais a psicologia é socialmente representada como uma profissão de ajuda que se realiza na clínica ${ }^{3,5,6}$. A análise sobre o sentido atribuído a essa ajuda possibilitou a identificação da ajuda curativa, orientadora e mediadora, sendo, cada uma delas, referida a uma concepção de sujeito e a distintas possibilidades de atuação em psicologia.

A ajuda curativa é a categoria com maior número de referências e apresenta o fazer em psicologia no campo da assistência à saúde que está, conceitualmente, referida a partir da ausência de doenças, no campo do patológico, em que a psicologia clínica historicamente se consolidou. Nessa perspectiva, os objetos da intervenção da psicologia são os pacientes, doentes, os sofrimentos, os transtornos e o fazer apontam para a possibilidade de tratar e de curar. Nessa posição, a psicologia é apreendida pelo imaginário do senso comum como uma prática voltada para a interioridade de sujeitos, que se realiza mediante relações duais e pressupõe uma suposta neutralidade em relação aos pacientes. Essa categoria de sentido assinala a representação da psicologia organizada em sua epistemologia científica, consolidada a partir do sujeito do lluminismo, referido por $\mathrm{Hall}^{2}$, na qual o ajudar assume o contorno do hegemônico modelo de assistência à saúde, curativo e hospitalocêntrico, que reproduz desigualdades sociais e econômicas. Mas, também, minimiza o sofrimento de muitos sujeitos enredados na teia da existência.
A cura e a salvação são, segundo Joel Birman ${ }^{12}$, dois registros forjados pelas sociedades ocidentais para dar conta do confronto do mal-estar da cultura contemporânea, próprias das questões relacionadas à existência e à morte que evidenciam a percepção sobre a finitude e, na sociedade ocidental, assumiu o lugar do mal ao longo da história. A civilização greco-romana estava ligada ao cuidar de si, no mundo, para se preparar para a morte e é apagada pelo cristianismo, com a promessa de vida eterna. Na modernidade, a questão do mal desloca-se do registro de salvação e fé religiosa para os registros de cura e ciência baseadas em evidências, que constroem referências padronizadas de bem e mal-estar para sustentar os efeitos de subjetivação "(...) a medicalização da vida, conjugada à psiquiatrização da existência, instrumentada pelas neurociências, encontra aqui o seu canteiro de obra"13.

A psicologia incorpora-se a essa cruzada, assumindo sua face curativa e, também, volta-se a combater o mal. A busca por atenuar o sofrimento humano associa-se às demandas de consumo, urgência, produtividade, refugiando-se, assim, em diagnósticos e na medicalização, em detrimento de aspectos considerados, ao longo da modernidade, inerentes à existência humana, como a percepção da tristeza, que assume a face de depressão e, hoje, está personificada como um dos males dos séculos $\mathrm{XX}$ e XXI, diferentemente das possibilidades transformadoras indicadas, por exemplo, pela poesia moderna de Vinicius de Moraes que, ao considerar o sujeito finito, vulnerável e capaz de saber criar, afirmava que "para fazer um samba com beleza, é preciso um bocado de tristeza, senão, não se faz um samba não", dando à criatividade, a sublimação, o poder transformador e elaborador das dores da existência humana.

Outra face da psicologia descrita como núcleo de sentido da categoria ajuda, pelos candidatos ao curso é a ajuda orientadora, que apresenta uma psicologia que aconselha, mostra, orienta, ensina e tem como objeto de estudo a pessoa, o próximo, o ser humano. Nessa categoria de respostas, podese observar que a percepção sobre o fazer do psicólogo já se distancia da neutralidade científica, implica a sua própria pessoa, seus valores e referências pessoais, colocados numa perspectiva idealizada, na qual o profissional se confunde com 
- amigo e anseia ser bom, ter sensibilidade, estar apto a tolerar e, acima de tudo, não julgar:

Saber ouvir e ter sensibilidade ao ouvir e respeito, em primeiro lugar, tentar entender o que se passa em diferentes mentes e, a partir daí, avaliar e mostrar os melhores meios de viver.

Compreender melhor determinadas situações e, assim, saber administrá-las, ser mais tolerante, poder ajudar as pessoas ouvindo-as e aconselhando-as.

Poder ajudar ao outro ensinando a saber se ajudar, para saber como se desenvolver.

Nessa perspectiva, o sentido de ajudar está diretamente ligado ao que Figueiredo e Santi ${ }^{19}$, identificaram como um sistema de docilização e domesticação do indivíduo, próprio do ideário disciplinar da modernidade, presentes, desde o século XIX, nas grandes agências sociais como escolas, fábricas, prisões, hospitais e, também, na psicologia, conforme referido anteriormente. Nessa leitura, o ajudar se associa a uma face do poder hegemônico, alienante, da sociedade contemporânea, que se esforça por reduzir os inconvenientes da liberdade e singularidade, mantendo certa ilusão de que somos cada vez mais livres e singulares ${ }^{19}$. Em vez do altruísmo, brotam, nessas narrativas, indicativos de uma ação voltada à alienação. O psicólogo que promove a ajuda orientadora está situado num contexto humanista que pressupõe o sujeito holístico, que imagina poder ser poupado do mal-estar de uma cultura.

outro sentido atribuído à ajuda, que emergiu do conjunto de narrativas estudadas, é a ajuda mediadora que coloca em evidência a noção de interioridade que se produz a partir de singularidades construídas nas relações sociais. Nesse sentido, o sujeito é detentor de um núcleo ou essência interior, mas ele não é autônomo ou autossuficiente e pode ser permanentemente modificado num diálogo contínuo com os mundos culturais:

(...) fazendo-o aprender a lidar com as próprias diferenças e dificuldades para facilitação de sua relação consigo e com o outro.

Compreender princípios básicos de sociedade, os conflitos e diferenças e saber aplicar em diversos contextos.

Através do atendimento e da assistência aos pacientes, realizar transformações sociais e facilitar alguns processos e situações, possibilitando ao paciente um maior entendimento de si mesmo e da sociedade em que está inserido.
Na ajuda mediadora, a ação do psicólogo está colocada a partir de uma posição de oferecimento, na qual o psicólogo se empresta ao outro para que algo novo se produza, numa posição que pode ser clínica, social ou organizacional.

Além de colocada como uma profissão de ajuda, os resultados confirmam a identificação de uma prática profissional associada à clínica, como afirma a literatura ${ }^{13,11,14}$. Uma clínica identificada com a psicanálise, com referência a conceitos como o inconsciente, ao método da escuta flutuante, à posição de certa imparcialidade, além da atitude de emprestar-se, referida anteriormente:

Analisar seu inconsciente e tentar buscar soluções para seus conflitos.

Ser psicólogo é ajudar os outros a se descobrir.

Escutando-o como ser humano e sem julgá-lo.

Ter capacidade de escutar, compreender o paciente sem, no entanto, julgá-lo ou interferir ativamente nas decisões do mesmo (...) levando-o a autorreflexão e a uma reforma interior.

(...) ajudar a desvendar e entender a vida e buscar melhorias no modo de encarar as adversidades e obstáculos.

As contribuições da psicanálise para a psicologia são inegáveis, especialmente para o desenvolvimento da prática clínica e da indissociabilidade entre 0 psíquico e o somático ${ }^{13}$. Entretanto, ao longo de suas histórias, tanto a psicanálise como a psicologia foram comprometidas com os ideários do cientificismo, da lógica neoliberal de mercado, que as aproximou, sobremaneira, da lógica curativa, patologizante da contemporaneidade em detrimento do caráter transformador, proposto por Freud, no início do século XIX. Essa psicanálise "original", por princípio, se opõe a essas psicologias que tentam explicar, de maneira universal, o funcionamento de sujeitos, de sua atividade mental a partir da resposta do sistema nervoso central ou de um sistema físico-químico, assim como à psicologia normativa, que exclui as singularidades em nome de padrões populacionais de conduta e investe em adestramentos. A psicanálise, enquanto prática clínica, propõe a possibilidade de fazer falar uma subjetividade, cada dia mais silenciada, pelas forças normatizadoras da nossa cultura ocidental ${ }^{20}$. 


\section{CONSIDERAÇÕES FINAIS}

O efeito desse histórico e eficiente processo de normatização da psicologia tem sido desafiado pela potência das novas formas de subjetivação que se colocam a partir do sujeito da pós-modernidade, ou da modernidade tardia, como preferia nomear Stuart Hall ${ }^{2}$. Desafiam esses modelos de psicologia que se ancoram em perspectivas essencialistas, na medida em que, múltiplas identidades são produzidas continuamente e permanentemente transformadas nas formas pelas quais somos representados ou interpelados nos sistemas culturais que nos rodeiam. Essas identidades garantem a produção do malestar, de contradições, de tensionamentos, de diferenças e, também, de felicidades e sentimentos provisórios de completude. Se por um lado, essa lógica, desarticula padrões e modelos identitários estáveis, por outro, abre múltiplas possibilidades de novas articulações, de transdisciplinaridades, de redes, de mudança permanente e com muita aprendizagem.

Os resultados desta pesquisa são indicativos de que 0 senso comum, representado pelos candidatos que escolhem pela psicologia neste curso, apreende a multiplicidade identitária da psicologia diferenciando suas possibilidades de colocação frente a diferentes concepções de sujeito. Entretanto, identificam sua prática à clínica de inspiração psicanalítica. Evidenciam a percepção de uma psicologia construída a partir de valores próprios da modernidade, fundamentados em um modelo de subjetividade de natureza binária que envolve sujeito/sociedade, interioridade/ exterioridade, saúde/doença. Abre-se com este estudo a necessidade de discutir modelos formativos que possam contemplar esse novo sujeito e investigar as possibilidades da psicologia, em seu natural talento para a pluralidade, prosperar na forma como é percebida e como se apresenta.

\section{CONTRIBUIÇÕES DOS AUTORES}

Daltro $M$ e Pondé $M$ contribuíram igualmente na concepção do projeto, coleta e análise dos dados e na construção do artigo.

\section{CONFLITOS DE INTERESSES}

Nenhum conflito financeiro, legal ou político envolvendo terceiros (governo, empresas e fundações privadas, etc.) foi declarado para nenhum aspecto do trabalho submetido (incluindo mas não limitandose a subvenções e financiamentos, conselho consultivo, desenho de estudo, preparação de manuscrito, análise estatística, etc).

\section{REFERÊNCIAS}

1. Lodieu MT, Scaglia H, Santos J. La representación social del psicólogo en estudiantes de universidades nacionales. In: XII Jornadas de Investigación y Primer Encuentro de Investigadores en Psicología del Mercosur, 2005, Buenos Aires. Buenos Aires: Facultad de Psicología - Universidad de Buenos Aires; 2005. p. 82-83.

2. Hall S. A identidade cultural na pós-modernidade. 11 .ed. Rio de Janeiro: DP\&A; 2006.

3. Arend MI, Motta RF. Representação social da psicologia e do psicólogo na sala de espera de uma clínica-escola. Estud Psicol. 201 4;31(3):415-23. doi: 10.1590/0103166X2014000300010

4. Lahm CR, Boeckel MG. Representação social do psicólogo em uma clínica-escola do município de Taquara/RS. Contextos clínic. 2008;1 (2):79-92. doi: 10.4013/ctc.20082.04

5. Bastos AVB, Gondim SMG. O Trabalho do Psicólogo no Brasil. Porto Alegre: Artmed; 2010.

6. Magalhães $M$, Straliotto $M$, Keller $M$, Gomes WB. Eu quero ajudar as pessoas: a escolha vocacional da psicologia. Psicol cien prof. 2001 ; 21 (2):10-27. doi: 10.1590/S141498932001000200003

7. Leme MAVS, Bussab VSR, Otta E. A representação social da psicologia e do psicólogo. Psicol cien prof. 1989;9(1):2935. doi: 10.1590/S1414-98931989000100009

8. Bortolomasi E, Liboni RG, Reis MF, Tamanaha HY, Guimaraes JL. Representação social da psicologia e do psicólogo sob o olhar da comunidade de Assis/SP - Brasil. Psicol Am Lat. 2008;(14):1-8.

9. Buela-Casal G, Roales-Nieto JG, Sierra JC, Bermúdez MP, Agudelo D, Bretón-López J et al. Imagen de la psicología como profesión sanitaria em profesores universitarios de psicología y de medicina. Pap Psicol. 2005;26(91):4-15.

10. Dimenstein M. A cultura profissional do psicólogo e o ideário individualista: implicações para a prática no campo da assistência pública à saúde. Estud psicol. 2000;5(1):95121. doi: $10.1590 /$ S1413-294X2000000100006 
11. Foucault M. A psicologia de 1850 a 1950. In: da Motta $M B$, organizador. Problematização do sujeito: psicologia, psiquiatria e psicanálise. 3.ed. Rio de Janeiro: Forense Universitária; 1999. p. 122-39.

12. Birman J. Cadernos sobre o mal: agressividade, violência e crueldade. Rio de Janeiro: Civilização Brasileira; 2009.

13. Rey FLG. Sujeito e subjetividade: uma aproximação histórico-cultural. São Paulo: Pioneira Thomson Learning; 2003.

14. Ganguilhem G. Que é a psicologia? Impulso; Revista de Ciências Sociais e Humanas. 1999;26(11):11-26.

15. Lacan J. Escritos. Rio de Janeiro: Jorge Zahar; 1998.

16. Yamamoto $O H$, Falcão JTR, Seixas PS. Quem é o estudante de psicologia do Brasil?. Avaliação Psicológica. $2011 ; 10(3): 209-32$

17. Birman J. Adolescência sem fim? Peripécias do sujeito num mundo pós-edipiano. In: Cardoso MR, Marty F, organizadoras. Destinos da adolescência. Rio de Janeiro: 7 Letras; 2008. p. 81-105.

18. Minayo MCS, organizadora. Pesquisa social: teoria, método e criatividade. 29.ed. Petrópolis: Vozes; 2010.

19. Figueiredo LCM, de Santi PLR. Psicologia, uma (nova) introdução: uma visão histórica da psicologia como ciência. 3.ed. São Paulo: EDUC; 2013.

20. Kehl MR. Sobre ética e psicanálise. São Paulo: Companhia das Letras; 2002. 